\author{
Marquette University \\ e-Publications@Marquette
}

\title{
Acculturation and Depression Among Hispanics: The Moderating Effect of Intercultural Competence
}

Lucas Torres

Marquette University, lucas.torres@marquette.edu

David Rollock

Purdue University - Main Campus

Follow this and additional works at: https://epublications.marquette.edu/psych_fac

Part of the Psychology Commons

\section{Recommended Citation}

Torres, Lucas and Rollock, David, "Acculturation and Depression Among Hispanics: The Moderating Effect of Intercultural Competence" (2007). Psychology Faculty Research and Publications. 28.

https://epublications.marquette.edu/psych_fac/28 
Marquette University

e-Publications@Marquette

\section{Psychology Faculty Research and Publications/College of Arts and Sciences}

This paper is NOT THE PUBLISHED VERSION; but the author's final, peer-reviewed manuscript. The published version may be accessed by following the link in th citation below.

Cultural Diversity and Ethnic Minority Psychology, Vol. 13, No. 1 (January 2007): 10-17. DOI. This article is (C) American Psychological Association and permission has been granted for this version to appear in e-Publications@Marquette. American Psychological Association does not grant permission for this article to be further copied/distributed or hosted elsewhere without the express permission from American Psychological Association.

\section{Acculturation and depression among Hispanics: The moderating effect of intercultural competence}

\section{Lucas Torres}

Department of Psychological Sciences, Purdue University;

\section{David Rollock}

Department of Psychological Sciences, Purdue University

Acknowledgement: Lucas Torres is now at the Department of Psychology, Marquette University.

This research is taken from the Lucas Torres's dissertation and was presented as a paper at the Inaugural Conference of the National Latino Psychological Association, November 2004, Scottsdale, AZ. The authors thank Ximena Arriaga, Judith Cohen Conger, and Kwong-Liem Karl Kwan for their help in developing this research.

The U.S. population has changed substantially over recent decades, with growing ethnic minority groups-particularly Hispanics-seeking new places in and redefining the American cultural 
mainstream. Consequently, mental health professionals and clinical researchers have become keenly aware of the importance of understanding the process of cultural adaptation. Arguably, most research addressing this need in the field has focused on cultural learning perspectives circumscribed by the construct of acculturation, which has provided useful information regarding global changes that take place when individuals acclimate to a new environment. However, it is necessary to expand these investigations to include the personal attributes and skills individuals employ rather than just the cultural content they acquire over a period of time (Berry, 2003; Sue, 2003). Competence-based variables, including general coping and intercultural competence, contribute to the knowledge base regarding the behavioral, cognitive, and emotional changes associated with cultural transition as well as the abilities and strategies that moderate negative psychological consequences. The growth of the Hispanic population provides an ideal opportunity to identify qualities that promote well-being and successful cultural interactions. The purpose of the present study was to examine these aspects of cultural adaptation in relation to depression.

\section{Cultural Adaptation}

Cultural adaptation typically has been characterized primarily by aspects of contact with and exposure to the mainstream culture, including skills deficits and lack of cultural knowledge (Torres \& Rollock, 2004). Acculturation, the most commonly studied adaptation variable, has been defined as the changes that an individual experiences as a result of being in contact with other cultures (Berry, Poortinga, Segall, \& Dasen, 1992). Zea, Asner-Self, Birman, and Buki (2003) identified five major acculturation domains frequently measured including behavior, cultural identity, knowledge, language, and values. More specifically, existing acculturation instruments have assessed language use, preference, and proficiency; social affiliation; daily living habits; cultural traditions and customs; communication styles; perceived prejudice and discrimination; and family socialization, pride, and acceptance (Zane \& Mak, 2003). English fluency has been a commonly referenced indicator of acculturation, as it is readily observable and likely to have a direct impact on interactions with the mainstream culture. Behavioral factors of acculturation, such as language use, have been distinguished from values as the latter may represent a more profound level of adaptation (Zea et al., 2003). Researchers also have used objective demographic variables, such as place of birth or generation level, amount of time spent in the mainstream culture, and socioeconomic status, as simpler proxies of cultural exposure, relying on these as initial predictors of outcomes and to target populations most in need of appropriate interventions (Escobar \& Vega, 2000). However, given the broad inconsistencies in the literature regarding the relationship between these culture-related variables and mental health (Rogler, Cortes, \& Malgady, 1991), it remains unclear whether acculturation or cultural exposure serves to ameliorate or exacerbate the development of psychological problems (Cuellar \& Roberts, 1997). Thus, the utility of acculturation and sociodemographic factors as general indicators of adaptation remain limited and research should be expanded to include other factors likely to influence acclimation to new cultural contexts.

In contrast, competence-based formulations of adaptation stress the fact that the mastery of particular sets of functional skills is key to psychological well-being (LaFromboise, Coleman, \& Gerton, 1993) and allow individuals to perform given cultural tasks or fulfill specific societal roles successfully (Ogbu, 1981). These characteristics promote the development of self-efficacy, self-worth, and styles of living 
that facilitate negotiating with life events (Tyler, Brome, \& Williams, 1991). Competence-based perspectives to cultural adaptation tend to cover two major areas. The first, general coping, involves mainstream-prescribed characteristics and refers to skills used within person-environment interactions. In an expansion of the stress and coping perspective, Tyler and Pargament (1982) proposed that coping functioned to develop an extended domain of mastery over the environment. An orientation toward (active) coping is characteristic of more energized individuals, who show greater initiative, planning, and vigorous efforts to determine their life course. This masteryoriented active problem-solving approach that describes general coping has been linked to higher functioning across various ethnic groups in the United States (Tyler et al., 1991).

The second factor within a competence-based framework involves intercultural competence, or proficiency regarding culturally relevant areas and group-specific skills that facilitate cultural interactions. Ethnic minority groups develop strategies characteristic of the traditional culture to facilitate accomplishment of significant tasks (Ogbu, 1981). Areas of importance and relevant strategies are identified that correspond to the particular practices, beliefs, and values of that cultural group. Ethnic minority individuals who develop skills for self-management and negotiating the mainstream from within these frameworks would be considered interculturally competent. For example, an interculturally competent first-generation Hispanic college student would have the ability to identify personal need, such as psychological distress, and be assertive enough to find and utilize available resources in the immediate environment (e.g., pastoral care or university counseling centers). Intercultural competence encompasses interactions with the mainstream culture; however, proficiency in maintaining person-environment relationships within the culture of origin are important as these intracultural interactions can serve as a source of support or added burden. This is particularly important if the skills associated with success in the mainstream (e.g., using mental health agencies) are not congruent with the traditional culture (e.g., use of folk remedies and healers), thus creating greater distress.

Zea et al. (2003) identified cultural competence, or knowledge about and ability to function in a particular culture, as a unique aspect of cultural adaptation and distinct from acculturation domains. Unfortunately, this formulation has not been examined as a predictor of mental health outcomes for Hispanics. Intercultural competence, on the other hand, has been found to be a significant predictor of acculturative stress among Hispanics in that greater proficiency in group-specific abilities was associated with less distress (Torres \& Rollock, 2004). Competence-based variables appear to make noteworthy contributions to the process of cultural adaptation and have an impact on Hispanic mental health. Thus, competence-based variables should be more directly and functionally relevant to predicting mental health distress among Hispanics adjusting to the U.S. cultural mainstream than simpler acculturation indicators.

\section{Depression}

Hispanics in the United States may be at great risk to suffer from mental health problems (Falcon \& Tucker, 2000). Data from the National Comorbidity Survey (Kessler et al., 1994), which used a national probability sample of adults, indicated that, although mental health profiles were comparable across ethnic groups, the lifetime and 30-day prevalence rates of a major depressive episode were highest among Hispanics, in particular Hispanic women, in the 15-44 age group (Blazer, Kessler, McGonagle, \& 
Swartz, 1994). Although significant differences among diverse Hispanic groups in prevalence rates of major depression have been noted in other large-scale studies (e.g., Moscicki, Rae, Regier, \& Locke, 1987) and some researchers have reported immigrating Hispanics with lower prevalence rates of depression than U.S.-born Hispanics and European Americans (Burnam, Telles, Karno, Hough, \& Escobar, 1987; Vega et al., 1998), in general, researchers have tended to find a higher number of depressive symptoms among Hispanics than among non-Hispanic Whites (Cuellar \& Roberts, 1997).

Research examining the relationship between acculturation and depression among Hispanics has yielded inconsistent findings. Several studies reported a negative relationship among various samples, including elderly persons (Falcon \& Tucker, 2000; Mahard, 1988; Zamanian et al., 1992) and adult men (Neff \& Hoppe, 1993) and women (Allen, Denner, Yoshikawa, Seidman, \& Aber, 1996; Masten, Penland, \& Nayani, 1994). Other studies have found a minimal relationship (Burnam et al., 1987) or a positive relationship (Cuellar \& Roberts, 1997; Golding \& Karno, 1988; Kaplan \& Marks, 1990). Apart from standard challenges associated with sample demographics (e.g., comparing the experiences of Mexican Americans and Puerto Ricans), these contradictory findings may reflect the substantial methodological differences across studies, including basic operationalization of the construct of acculturation (e.g., as a unidimensional vs. bidimensional construct) and the specific domains of acculturation presumed important to measure (e.g., language use vs. cultural preferences vs. time in the United States vs. more comprehensive instruments).

In contrast, a more consistent pattern is evident from the fewer studies employing competencerelated variables as predictors of depression. General coping or active problem-solving has been associated with lower levels of depressive symptomatology among a Hispanic population (Otero, Tyler, \& Labarta, 1986), whereas passivity, a lack of proactive behaviors, and emotion-focused coping styles were related to greater depression across ethnic minority groups, including Hispanics (Stein \& Nyamathi, 1999). Unfortunately, no well-designed studies have been published that compare directly the relative predictive power of acculturation-related and competence-related constructs for this important mental health outcome.

To address that gap, the present study examines the roles of acculturation, general coping, and intercultural competence in predicting depression among Hispanics. Based on previous reports indicating its efficacy in predicting acculturative stress among Hispanics (Torres \& Rollock, 2004), intercultural competence was expected to be a significant predictor of depression. That is, it was hypothesized that intercultural competence, because of its emphasis on group-specific abilities, would contribute significant variance above that already accounted for by general coping, acculturation, and demographic variables (generation level, annual income, and years lived in the United States) in the prediction of depression.

\section{Methods}

\section{Participants}

The participants were adult Hispanic volunteers from a moderately sized Midwestern city, recruited through local Hispanic churches, community centers that serviced mainly Hispanics, and Universitybased Hispanic organizations. According to the most recent U.S. census figures, Hispanics constituted approximately $5 \%$ of the population in this largely European American city and earned a median annual 
income of $\$ 11,112$, compared with the local median income of $\$ 38,652$. In this sample of 96 adults, $54 \%$ were male, and $46 \%$ were female. Ages ranged from 18 to 62 years, with the mean age being 28.71 years $(S D=9.7)$. Mexicans, Mexican Americans, and/or Chicanos comprised $89 \%$ of the participants. The rest of the sample included Puerto Ricans, Central or South Americans, and other nationalities of Hispanic heritage. Fifty-eight participants were members of the first generation to live in the United States, 28 were second generation, and 5 were third generation. Although the largest portion of individuals indicated having lived in the United States for $<10$ years ( $82 \%)$, the amount of time spent in this country ranged from $<1$ year to 32 years across the entire sample. Moreover, $73 \%$ of the sample reported earning an annual income of $\$ 20,000$ or less. Given the choice, the majority of participants (90\%) chose to respond in Spanish to the study instruments, making it difficult to compare groups based on language used to complete the questionnaires.

\section{Materials}

\section{Cultural Life Style Inventory}

The Cultural Life Style Inventory (CLSI) is a 29-item self-report scale designed to measure acculturation among Hispanics in the United States. Although the CLSI can yield several subscale scores, responses to the ordinal options were averaged to create a single acculturation score to facilitate multivariate analyses and represented a unidimensional acculturation scale. A low score indicated low acculturation and a high score meant high acculturation. Cronbach's alpha coefficient of the unidimensional scale's reliability has been reported to be 0.96 (Magana et al., 1996). Validation of the CLSI has been reported previously by showing, as expected, increased acculturation scores across successive generations (Mendoza, 1989).

\section{Behavioral Attributes Of Psychosocial Competence}

The Behavioral Attributes of Psychosocial Competence (BAPC) scale is a self-report measure that consists of 36 forced-choice items and 3 fillers. The BAPC was developed to evaluate aspects of psychocultural competence in the mainstream United States and has been used with various ethnic minority groups. Competent coping style items are given a score of 1 and the opposite are scored as 0. The possible range of item scores is from 0 to 36. High scores are associated with increased use of general active coping skills. The internal consistency of this measure has been reported to be .82 as assessed by Cronbach's alpha. This measure has been translated and validated for use with Spanishspeaking populations (Otero, Tyler, \& Labarta, 1986).

\section{Intercultural Competence Concerns}

The Intercultural Competence Concerns (ICC) scale, a 24-item subscale of the Cultural Adjustment Difficulties Checklist (Sodowsky \& Lai, 1997), asks respondents to indicate how much concern they have about their effectiveness in social, cultural, academic, and career matters in a predominantly European American context. Respondents rate themselves on items using a Likert-type response format ranging from 1 (very inaccurate description) to 6 (very accurate description). Possible scores range from 24 to 144, with higher scores reflecting greater concern and thus less competence. The internal consistency reliability of the ICC has been reported to be .88 (Sodowsky \& Lai, 1997). Although this instrument was originally developed to understand intercultural competence among Asian immigrants, it has been adapted and validated for Hispanic populations (Maestas, 2000; Orozco, 1995). 


\section{Center for Epidemiologic Studies Depression}

The Center for Epidemiologic Studies Depression (CES-D) scale is a 20-item self-report inventory of depressive symptomatology (Radloff, 1977). The possible range of scores is 0 to 60 . Higher scores indicate more symptoms, weighted by frequency of occurrence during the past week. Internal consistency coefficient alphas of .85 in the general population and .90 in a patient sample have been reported. The CES-D was not designed for clinical diagnosis but is based on symptoms of depression present in clinical cases, making it sensitive to levels of severity. A cutoff score of 16 has been established to differentiate between clinical and nonclinical descriptions of depression, with higher scores indicating pathology (Posner, Stewart, Marin, \& Perez-Stable, 2001). The CES-D has become one of the most popular and commonly used instruments for assessing depressive symptomatology among the Hispanic population partly because the scale has been reported to reduce the contaminating effects of physical health symptom items that are found in other measures (Vega \& Rumbaut, 1991).

\section{Procedure}

All instruments were made available to participants in English and Spanish. A double translation method (Marín \& Marín, 1991) was used to translate the ICC into Spanish, since this instrument did not already have available translations. Two different professional individuals who were well versed in English and Spanish languages as well as Hispanic and mainstream American cultures translated both instruments separately. Item reliability analysis for the Spanish versions of the ICC revealed Cronbach's $\alpha=.83$. Reliability analyses for the CLSI, BAPC, and CES-D showed Cronbach's $\alpha=.96, .83$, and .86, respectively. Participants were asked to complete a packet of questionnaires that consisted of the CLSI, the BAPC, the CES-D, the ICC, and a background information form. The questionnaires were counterbalanced to minimize potential order effects. Appropriate precautions were taken to maintain confidentiality of the participants. When questionnaires were completed, participants were compensated with $\$ 10$ in cash.

\section{Results}

\section{Preliminary Analyses}

The hypotheses were examined using hierarchical multiple regressions, following the assumptions of multivariate analysis. Because the CES-D (skewness $=.94, p<.01$ ) and the CLSI (skewness $=1.13, p<$ .01 ) both were significantly positively skewed whereas the BAPC (skewness $=-.61, p<.05$ ) was negatively skewed, square root transformations were conducted to approximate normality for these variables. For the BAPC, the nature of the transformations involved reflecting the distribution, which resulted in a change of direction of the original scores. That is, the distribution of scores for the BAPC (square root [SQRT]) was the opposite of the original structure of the scale, indicating that low scores now meant higher competence. The BAPC (SQRT) brought the distribution back into an approximation of normality and therefore was used in the hierarchical multiple regressions. The findings of skewness with the CES-D and the BAPC are consistent with past reports (Neff \& Hoppe, 1993; Tyler \& Pargament, 1982). Because the sample consisted of primarily first-generation immigrants, it was not surprising that the CLSI was skewed toward the low acculturation side of the spectrum.

Table 1 shows the original means and standard deviations of the main variables. Depression scores averaged close to the clinical cutoff, suggesting that the participants experienced substantial levels of 
depressive symptoms. In fact, approximately $40 \%(n=38)$ of participants scored at or above clinical levels of depression. The general coping scores fell in a range that has been suggested to describe individuals with significant psychosocial difficulties and inadequate active coping abilities (Tyler \& Pargament, 1982). This is consistent with previous reports indicating minimal use of active coping techniques by Hispanics (Diaz-Guerrero, 1979). Norms for the ICC have not been published; therefore, it was difficult to ascertain how this sample compares to others in levels of self-perceived effectiveness in important intercultural contexts.

Table 1. Means and Zero-Order Correlations Among Main Variables ( $N=96)$

\begin{tabular}{|l|r|r|r|r|r|r|r|r|}
\hline Variable & 1 & 2 & 3 & 4 & 5 & 6 & 7 & 8 \\
\hline 1. Income & - & -.08 & $.21^{*}$ & $.27^{* *}$ & .06 & .01 & -.10 & -.12 \\
\hline 2. Generation level & & - & $-26^{* *}$ & $.20^{*}$ & .13 & -.18 & -.14 & -.13 \\
\hline 3. Age & & & -16 & .16 & -.09 & -.08 & -.12 & -.03 \\
\hline 4. Years in United States & & & & & $48^{* * *}$ & -.11 & -.07 & $-.29^{* *}$ \\
\hline 5. Acculturation & & & & & - & -.12 & .06 & $-.27^{* *}$ \\
\hline 6. General coping & & - & & & & & .13 & $.57^{* * *}$ \\
\hline 7. Intercultural competence & & & & & & &.- & $17^{*}$ \\
\hline 8. Depression & & & & & & & - & 15.22 \\
\hline$M$ & - & - & 28.71 & 5.86 & 2.21 & 24.26 & 56.07 & 13.91 \\
\hline$S D$ & - & - & 9.68 & 6.69 & .62 & 6.47 & 15.55 & 9.62 \\
\hline
\end{tabular}

${ }^{*} p<.05 .{ }^{* *} p<.01 .{ }^{* * *} p<.001$.

Table 1 also contains zero-order correlations, indicating that more years in the United States was positively associated with increased income, acculturation, and generation level, as expected. Also, income increased predictably with age, and, consistent with the characteristics of the current sample, age was associated with earlier generations. Generation level, annual income, and years lived in the United States were the demographic variables included in the analyses because of previous evidence showing their predictive impact with the dependent variables.

\section{Depression}

It was hypothesized that intercultural competence would account for variance above and beyond that of general coping, acculturation, and demographic variables. With CES-D as the dependent variable (see Table 2), the hierarchical multiple regression indicated that after Step 1, generation level, income, and years lived in the United States generated $R^{2}=.09, F(3,92)=3.07, p<.03$ (adjusted $R^{2}=.06$ ). At Step 2, with the addition of the CLSI, $R^{2}=.11, F(1,91)=2.90, p<.03$ (adjusted $R^{2}=.07$ ), but the change in variance at Step 2 was not significant (Fchange $=2.28, p<.13$ ). However, the addition of the BAPC (SQRT) in Step 3 showed a significant increase in accounted variance, $R^{2}=.39, F(1,90)=11.32, p<.001$ (adjusted $R^{2}=.35 ; F$ change $=39.99, p<.001$ ). Contrary to predictions, in the final step, adding ICC did not contribute a significant amount of variance (Fchange $=1.25, p<.27$ ), but the equation remained significant with $R^{2}=.40, F(1,89)=9.66, p<.001$ (adjusted $R^{2}=.35$ ). With all predictors in the equation, BAPC (SQRT) was the only significant contributor. Because intercultural competence did not increment prediction beyond that afforded by general competence and demographic indicators of acculturation, the original hypothesis was not supported. 
Table 2. Hierarchical Regression Analysis for Variables Predicting Depression $(N=96)$

\begin{tabular}{|c|c|c|c|}
\hline Variable & $B$ & $S E B$ & $\beta$ \\
\hline \multicolumn{4}{|l|}{ Step 1} \\
\hline Years lived in United States & -0.05 & 0.02 & $-.26^{*}$ \\
\hline Annual income & -0.07 & 0.15 & -.05 \\
\hline Generation level & -0.18 & 0.22 & -.08 \\
\hline \multicolumn{4}{|l|}{ Step 2} \\
\hline Years lived in United States & -0.03 & 0.02 & -.17 \\
\hline Annual income & -0.09 & 0.15 & -.07 \\
\hline Generation level & -0.17 & 0.22 & -.08 \\
\hline Acculturation & -1.07 & 0.71 & -.17 \\
\hline \multicolumn{4}{|l|}{ Step 3} \\
\hline Years lived in United States & -0.02 & 0.02 & -.15 \\
\hline Annual income & -0.10 & 0.12 & -.07 \\
\hline Generation level & 0.01 & 0.19 & .01 \\
\hline Acculturation & -0.79 & 0.59 & -.13 \\
\hline General coping (SQRT) & 0.69 & 0.11 & $.53^{* * *}$ \\
\hline \multicolumn{4}{|l|}{ Step 4} \\
\hline Years lived in United States & -0.03 & 0.02 & -.15 \\
\hline Annual income & -0.08 & 0.12 & -.06 \\
\hline Generation level & 0.04 & 0.19 & .02 \\
\hline Acculturation & -0.87 & 0.60 & -.14 \\
\hline General coping (SQRT) & 0.68 & 0.11 & $.52^{* * *}$ \\
\hline Intercultural competence & 0.01 & 0.01 & .10 \\
\hline
\end{tabular}

Note. $R^{2}=.09$ for Step $1(p s<.03) ; R^{2}=.11$ for Step $2(p s<.13)$;

$R^{2}=.39$ for Step $3(p s<.001) ; R^{2}=.40$ (adjusted $\left.R^{2}=.35\right)$ for Step $4(p s<.27)$. SQRT $=$ square root.

${ }^{*} p<.05 .^{* * *} p<.001$.

Although the CLSI and the CES-D were significantly correlated at the zero-order level, the lack of significance when the CLSI was entered into the hierarchical multiple regression equation predicting CES-D was striking and inconsistent with previous studies. Baron and Kenny (1986) suggest that a moderator variable is present when there is an unexpectedly weak or inconsistent relation between predictor and criterion. Moderators can be defined as third variables that affect the direction and/or strength of the relationship between two other factors. A moderator effect can be represented as the interaction between the predictor and the moderator that influences the criterion. Given this description and the findings reported previously, it was suspected that intercultural competence might have been altering the relationship between acculturation and depression.

A supplementary hierarchical multiple regression was conducted to test for a moderator effect in which the CLSI, intercultural competence, and an interaction term (CLSI $\times$ Intercultural Competence)

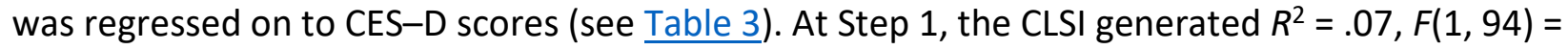
$7.25, p<.01$ (adjusted $R^{2}=.06$ ). At Step 2, with the addition of intercultural competence, $R^{2}=.11, F(1$, 93 ) $=5.47, p<.01$ (adjusted $R^{2}=.09 ; F$ change $=3.49, p<.07$ ). In the final step, the interaction term 
contributed a significant amount of variance ( $F$ change $=13.47, p<.001$ ) and increased $R^{2}=.22, F(1$, $92)=8.62, p<.001$ (adjusted $R^{2}=.19$ ). The significance of the interaction term (CLSI $\times$ Intercultural Competence) in predicting CES-D scores suggested the presence of a moderator that altered the relationship between acculturation and depression.

Table 3. Hierarchical Regression Analysis Testing and Interaction Effect (Acculturation $\times$ Intercultural Competence) in Predicting Depression ( $N=96)$

\begin{tabular}{|l|r|r|r|}
\hline Variable & $B$ & SE B & $\beta$ \\
\hline Step 1 & & & \\
\hline Acculturation & -1.67 & 0.62 & $-.27^{* *}$ \\
\hline Step 2 & & & \\
\hline Acculturation & -1.75 & 0.61 & $-.28^{* *}$ \\
\hline Intercultural competence & 0.02 & 0.01 & .18 \\
\hline Step 3 & & & \\
\hline Acculturation & -1.68 & 0.58 & $-.27^{* *}$ \\
\hline Intercultural competence & 0.02 & 0.01 & $.19-$ \\
\hline Interaction & 0.13 & 0.04 & $.34^{* * *}$ \\
\hline
\end{tabular}

Note. $R^{2}=.08$ for Step 1 ( $\left.p s<.01\right) ; R^{2}=.1$ for Step 2 ( $p s<.07$ );

$R^{2}=.22$ (adjusted $\left.R^{2}=.19\right)$ for Step $3(p s<.001)$.

${ }^{*} p<.05 .{ }^{* *} p<.01 .{ }^{* * *} p<.001$.

To better understand this interaction effect, the sample was divided into high and low acculturation and high and low intercultural competence groups, based on median splits. Figure 1 illustrates the interaction between the two cultural adjustment variables on depression by indicating the average CES-D scores for the high and low groups of acculturation and intercultural competence. Hispanics high in acculturation and intercultural competence tended to experience relatively few depressive symptoms $(M=12.3, S D=8.8)$, whereas those low in acculturation and high in intercultural competence reported depression well above clinical cutoffs $(M=18, S D=9.9)$. In contrast, those with low intercultural competence, regardless of acculturation level, showed average depression scores close to the clinical cutoff (high acculturation $M=15.3, S D=9.2$; low acculturation $M=15.8, S D=$ 10.3). These findings demonstrate the importance of taking into consideration the synergistic effects of acculturation and specific competence.

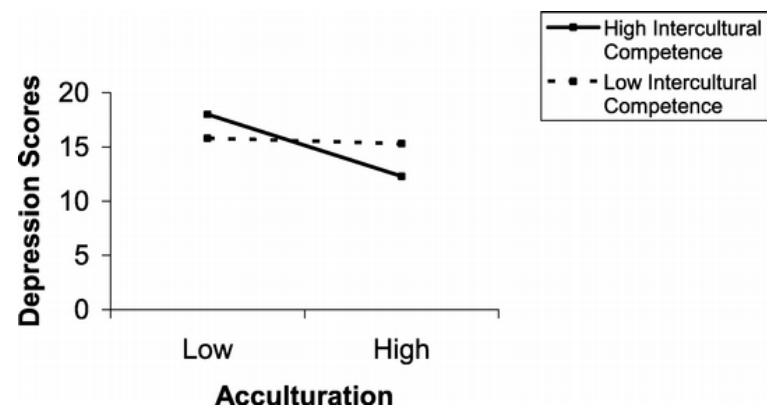

Figure 1. Interaction effect of acculturation and intercultural competence on depression among Hispanics. High and low groups were divided based on median splits with average CES-D scores plotted 


\section{Discussion}

This research was designed to disentangle the contributions of variables representing three different conceptualizations of individual differences in cultural adaptation: common demographic indicators, acculturation, and competence, both general and intercultural. The present study not only confirmed the fact that variables reflecting degrees of cultural transition do predict significant mental health outcomes among Hispanics, but also showed that competence-based variables contribute to predicting depression above and beyond levels achieved with more traditional variables, in complex ways.

Furthermore, a multidimensional conceptualization of acculturation is likely to foster a similar pattern of results given previous findings suggesting a lack of significant difference between unidimensional and bidimensional measures in predicting Hispanic distress (Torres \& Rollock, 2000).

At the most basic level, general coping was the best single predictor of levels of depressive symptomatology, in that active problem-solving was strongly associated with fewer symptoms. This finding is thoroughly consistent with the extensive literature confirming that active coping effectively promotes psychological well-being (Tyler et al., 1991) and therefore is a central feature of empirically supported treatments for depression (Hollon, Haman, \& Brown, 2002). Not only are increased energy, initiative, and planfulness characteristic of active problem-solvers and the antithesis of the classic vegetative signs of depression, but the absence of these qualities is a traditional marker of deviation from American mainstream notions of competent functioning (cf. Ramirez, 1991).

Whereas U.S. ideals and values promote independence and assertiveness, Diaz-Guerrero (1979) found that Hispanics, especially individuals of Mexican descent, preferred a coping style emphasizing passive endurance or accommodative self-modification, perhaps as a response to demands from the mainstream culture rather than as a feature of their traditional culture. This coping style may suggest a particular risk for psychological distress among Hispanics adjusting to the U.S. context, as reflected in the elevated level of depressive symptoms across this entire sample. Cultural values determine which resources are appropriate to meet adaptational demands, as well as the societal consequences for adopting certain adaptational styles (Hobfoll, 1998). Forms of coping that are considered maladaptive in some contexts can represent adaptive use of resources in other contexts. For example, although American society may generally favor the active problem-solver, efforts of aggressive copers to alter their circumstances could turn out to be problematic within a dominant society that does not accommodate to the needs of acculturating individuals (Berry, 2003). These individuals eventually may come to withdraw themselves from the mainstream, based on their fruitless experiences. In contrast, individuals who are patient, flexible, and accommodating enough to meet changing contextual demands are likely to adapt successfully (Ramirez, 1991). Thus, susceptibility to depressive symptoms may be influenced not only by the ability to plan competently and problem-solve actively to meet desired goals in the new context, but also by the capacity to accommodate and patiently adapt to the new mainstream by the selective use of specific valued traditional cultural patterns.

Consistent with this logic but not contemplated in the original hypotheses, intercultural competence was found to moderate the relationship between acculturation and depression. Naturally, those interculturally competent individuals who actually adopt ways of the mainstream (i.e., acculturate) should experience less stress; in this study, they showed fewer depressive symptoms than any other group. In contrast, difficulty establishing effective person-environment relationships may set the stage 
for a constant low level of distress, as suggested by the consistent subclinical level of symptoms seen for those respondents with low intercultural competence, regardless of level of acculturation. Depressive symptoms become most pronounced for those who actually have the capacity to establish these effective person-environment relationships but are unable or unwilling to adopt mainstream activities. For Hispanics in particular, Jenkins (1997)described the struggle to maintain a rhythm of life, or an individual's sense of involvement in the flow of everyday activities. This sense of rhythm may have been threatened by the feelings of suffering and detachment combined with wanting to sustain vital energy and make social connections.

Viewed another way, the consequences associated with a significant disparity between acculturation and intercultural competence could be further exacerbated when there is an emphasis on adopting mainstream elements. If acculturation is viewed as an important and valued aspect of cultural adaptation by a particular cultural group-voluntary immigrants with plans to settle their families in the new area would be a prime example-then failure to meet those expectations, although having a sense of proficiency to make such connections, could have considerable psychological ramifications. If this is even partly true, then accounting for acculturation goals becomes a crucial factor in cultural adaptation as it influences the mainstream elements an individual chooses to incorporate into daily life, and the coping skills available to the individual when negotiating with the new environment.

This conceptualization of personal/contextual/cultural fit does suggest an important set of limitations to the present study. The description of depression and related symptom expression is based on a mainstream understanding of the problem that may not accurately reflect manifestations found in other cultural groups. It has been documented that some ethnocultural minority groups, including Hispanics, express psychological concerns through somatic symptoms: The interpretation or articulation of pain and other physical sensations may occur with mood changes or when one experiences personal and social problems (Vega \& Rumbaut, 1991). Furthermore, as cited above, depression is characterized as reflecting passive approaches to adaptational challenges; this conceptualization therefore may represent a cultural component as well as traditional pathology. Fully appreciating the unique presentation of mood symptoms across ethnic groups requires sensitivity to the different formulations and perceptions of what it means to experience these difficulties (Weingartner, Robison, Fogel, \& Gruman, 2002). Also, the present study was constrained by the demographic characteristics of the participants sampled, particularly in areas of language preferences and fluency, thus limiting the generalizability of the results. These findings may best characterize individuals similar in ethnicity and the geographic and cultural contexts represented by the moderately sized Midwestern city from which the present participants were drawn.

\section{Conclusion}

The dynamic and multifaceted nature of cultural adaptation, bound by historical and social context, makes it difficult to identify a single set of rules, resources, and demands that predict those processes invariably over time and across groups ( $\mathrm{Hobfoll}, 1998)$. The integration of competence-based factors with aspects of cultural-learning provides rich insights into the complexities of cultural adaptation. This approach expands knowledge beyond simplistic proxy variables (e.g., language spoken at home) or aspects of cultural contact and cultural exposure (e.g., number of years spent in the United States) that, although important facets of transition, may be rudimentary. Competence-based approaches to 
cultural adaptation provide a description of the functional skills associated with adjustment and introduce adaptive personal attributes within a cultural context. Thus, Hispanic adaptation can be understood best when there is an appreciation for group-specific strengths, abilities, and community resources that are available to individuals when interacting in the mainstream American culture (Torres \& Rollock, 2004).

Such a molecular level of analysis (cf. Rollock, 2000) of cultural processes may help resolve some of the inconsistencies found in the literature on Hispanic mental health. Defining group-specific competencies becomes an important aspect of conceptualizing cultural adaptation as ethnic minority groups develop their own definition of success based on their own within-group cultural traditions, values, and goals (Ogbu, 1981). Culturally relevant skills directly impact the development of appropriate clinical intervention strategies. Competence-related variables seem more relevant to the prevention and management of depressive symptoms among Hispanic clients than simplistic indicators of acculturation status. For instance, communication ability, an area of perceived proficiency compatible with conceptualizations of success, becomes a more salient factor in the expression of distress than language preference. Of course, future researchers should examine the full range of psychological problems that Hispanic immigrant groups may exhibit. Following a molecular approach, it is important to remember the contextual and mediational role of intercultural competence in social and cultural adjustment. Intercultural competence was measured in this study by self-reported concerns about abilities in particular areas. However, future research will be needed to determine which domains of competence actually protect individuals facing particular sets of challenges and whether any constellations of competencies actually put individuals at risk for distress because of mismatches with environmental demands.

\section{Footnotes}

1 Comparisons of demographic variables based on the language chosen to take the questionnaires showed minimal differences except for the number of years lived in the U.S. (Spanish $M=$ $4.91, S D=4.85$; English $M=15.02, S D=12.10)$. As one of the goals of the present study was to include participants across various levels of acculturation, competence, and functioning, the sample was not separated based on language preferences to maintain adequate variability. Also, the use of double-translation procedures and previously validated Spanish measures provides some assurance of equivalent content across languages.

\section{References}

Allen, L., Denner, J., Yoshikawa, H., Seidman, E., \& Aber, J. L. (1996). Acculturation and depression among Latina urban girls. In B. J. R.Leadbeater, \& N.Way (Eds.), Urban girls: Resisting stereotypes, creating identities (pp. 337-352). New York: New York University Press.

Baron, R. M., \& Kenny, D. A. (1986). The moderator-mediator variable distinction in social psychological research: Conceptual, strategic, and statistical considerations. Journal of Personality and Social Psychology, 51, 1173-1182.

Berry, J. W. (2003). Conceptual approaches to acculturation. In K. M.Chun, P. B.Organista, \& G.Marin (Eds.), Acculturation: Advances in theory, measurement, and applied research (pp. 17-37). Washington, DC: American Psychological Association. 
Berry, J. W., Poortinga, Y. H., Segall, M. H., \& Dasen, P. R. (1992). Cross-cultural psychology: Research and applications. New York: Cambridge University Press.

Blazer, D. G., Kessler, R. C., McGonagle, K. A., \& Swartz, M. S. (1994). The prevalence and distribution of major depression in a national community sample: The national comorbidity survey. American Journal of Psychiatry, 151, 979-986.

Burnam, M. A., Hough, R. L., Karno, M., Escobar, J. I., \& Telles, C. A. (1987). Acculturation and lifetime prevalence of psychiatric disorders among Mexican Americans in Los Angeles. Journal of Health and Social Behavior, 28, 89-102.

Cuellar, I., \& Roberts, R. E. (1997). Relations of depression, acculturation and socioeconomic status in a Latino sample. Hispanic Journal of Behavioral Sciences, 19, 230-238.

Diaz-Guerrero, R. (1979). The development of coping style. Human Development, 22, 320-331.

Escobar, J. I., \& Vega, W. A. (2000). Mental health and immigration's AAAs: Where are we and where do we go from here?Journal of Nervous and Mental Disease, 188, 736-740.

Falcon, L. M., \& Tucker, K. L. (2000). Prevalence and correlates of depressive symptoms among Hispanic elders in Massachusetts. Journal of Gerontology, 55, S108-S116.

Golding, J. M., \& Karno, M. (1988). Gender differences in depressive symptoms among Mexican Americans and non-Hispanic Whites. Hispanic Journal of Behavioral Sciences, 10, 1-19.

Hobfoll, S. E. (1998). Stress, culture and community: The psychology and philosophy of stress. New York: Plenum Press.

Hollon, S. D., Haman, K. L., \& Brown, L. L. (2002). Cognitive-behavioral treatment for depression. In I. H.Gotlib \& C. L. Hamen (Eds.), Handbook of depression (pp. 383-403). New York: Guilford Press.

Jenkins, J. H. (1997). Subjective experience of persistent schizophrenia and depression among US Latinos and Euro-Americans. British Journal of Psychiatry, 171, 20-25.

Kaplan, M. S., \& Marks, G. (1990). Adverse effects of acculturation: Psychological distress among Mexican American young adults. Social Science and Medicine, 31, 1313-1319.

Kessler, R. C., McGonagle, K. A., Zhao, S., Nelson, C. B., Hughes, M., Eshleman, S., et al. (1994). Lifetime and 12-month prevalence of DSM-III-R psychiatric disorders in the United States. Archives of General Psychiatry, 51, 8-19.

LaFromboise, T., Coleman, H. L. K., \& Gerton, J. (1993). Psychological impact of biculturalism: Evidence and theory. Psychological Bulletin, 114, 395-412.

Maestas, M. V. (2000). Acculturation and ethnic identity measures for Latinos and Asian-Americans: Analyses of methodology and psychometrics. Unpublished doctoral dissertation. University of Nebraska-Lincoln.

Magana, J. R., de la Rocha, O., Amsel, J., Magana, H. A., Fernandez, M. I., \& Rulnick, S. (1996). Revisiting the dimensions of acculturation: Cultural theory and psychometric practice. Hispanic Journal of Behavioral Sciences, 18, 444-468.

Mahard, R. E. (1988). The CES-D as a measure of depressive mood in the elderly Puerto Rican population. Journal of Gerontology, 43, 24-25.

Marín, G., \& Marín, B. V. (1991). Research with Hispanic populations. Newbury Park, CA: Sage.

Masten, W. G., Penland, E. A., \& Nayani, E. J. (1994). Depression and acculturation in Mexican American women. Psychological Reports, 75, 1499-1503.

Mendoza, R. H. (1989). An empirical scale to measure type and degree of acculturation in MexicanAmerican adolescents and adults. Journal of Cross-Cultural Psychology, 20, 372-385. 
Moscicki, E. K., Rae, D. S., Regier, D. A., \& Locke, B. Z. (1987). The Hispanic Health and Nutrition Survey: Depression among Mexican Americans, Cuban Americans, and Puerto Ricans. In M.Garcia \& J.Arana (Eds.), Research agenda for Hispanics (pp. 145-159). Chicago: University of Illinois Press.

Neff, J. A., \& Hoppe, S. (1993). Race/ethnicity, acculturation, and psychological distress: Fatalism and religiosity as cultural resources. Journal of Community Psychology, 21, 3-20.

Ogbu, J. (1981). Origins of human competence: A cultural-ecological perspective. Child Development, 52, 413-429.

Orozco, L. D. (1995). Factors contributing to the psychological adjustment of Mexican-American college students. Dissertation Abstracts International, 56, 1714.

Otero, R. F., Tyler, F. B., \& Labarta, M. M. (1986). A configuration of psychosocial competence in a Puerto Rican college sample. Revista Interamericana de Psicologia, 20, 41-54.

Posner, S. F., Stewart, A. L., Marin, G., \& Perez-Stable, E. J. (2001). Factor variability of the Center for Epidemiological Studies Depression Scale (CES-D) among urban Latinos. Ethnicity and Health, 6, 137-144.

Radloff, L. S. (1977). The CES-D Scale: A self-report depression scale for research in the general population. Applied Psychological Measurement, 1, 385-401.

Ramirez, M. (1991). Psychotherapy and counseling with minorities: A cognitive approach to individual and cultural differences. New York: Pergamon Press.

Rogler, L. H., Cortes, D. E., \& Malgady, R. G. (1991). Acculturation and mental health status among Hispanics: Convergence and new directions for research. American Psychologist, 46, 585-597.

Rollock, D. (2000). Social context of emotion in Black adolescents: Impact of principles on process and products. In C. C.Yeakey (Ed.), Advances in education in diverse communities: Research, policy, and praxis (Vol. 1, pp. 3-14). Stamford, CT: JAI Press.

Sodowsky, G. R., \& Lai, E. W. M. (1997). Asian immigrant variables and structural models of crosscultural distress. In A.Booth, A. C.Crouter, \& N.Landale (Eds.), Immigration and the family: Research and policy on U.S. immigrants (pp. 211-234). Mahwah, NJ: Erlbaum.

Stein, J. A., \& Nyamathi, A. (1999). Gender differences in relationships among stress, coping, and health risk behaviors in impoverished, minority populations. Personality and Individual Differences, 26, 141-157.

Sue, S. (2003). Foreword. In K. M.Chun, P. B.Organista, \& G.Marin (Eds.), Acculturation: Advances in theory, measurement, and applied research (pp. xvii-xxi). Washington, DC: American Psychological Association.

Torres, L., \& Rollock, D. (2000, August). Dimensions and domains of Hispanic acculturation in the prediction of distress. Poster session presented at the 108th Annual Convention of the American Psychological Association, Washington, DC.

Torres, L., \& Rollock, D. (2004). Acculturative distress among Hispanics: The role of acculturation, coping, and intercultural competence. Journal of Multicultural Counseling and Development, 32, 155-167.

Tyler, F. B., Brome, D. R., \& Williams, J. E. (1991). Ethnic validity, ecology, and psychotherapy: A psychological competence model. New York: Plenum Press.

Tyler, F. B., \& Pargament, K. I. (1982). The behavioral attributes of psychosocial competence. Unpublished manuscript, University of Maryland. 
Vega, W. A., Kolody, B., Aguilar-Gaxiola, S., Alderete, E., Catalano, R., \& Caraveo-Anduaga, J. (1998). Lifetime prevalence of $D S M-I I I-R$ psychiatric disorders among urban and rural Mexican Americans in California. Archives of General Psychiatry, 55, 771-782.

Vega, W. A., \& Rumbaut, R. G. (1991). Ethnic minorities and mental health. Annual Review of Sociology, 17, 351-383.

Weingartner, K., Robison, J., Fogel, D., \& Gruman, C. (2002). Depression and substance use in a middle aged and older Puerto Rican population. Journal of Cross-Cultural Gerontology, 17, 173-193.

Zamanian, K., Thackrey, M., Starrett, R. A., Brown, L. G., Lassman, D. K., \& Blanchard, A. (1992). Acculturation and depression in Mexican-American elderly. Clinical Gerontologist, 11, 109-121.

Zane, N., \& Mak, W. (2003). Major approaches to the measurement of acculturation among ethnic minority populations: A content analysis and an alternative empirical strategy. In K. M.Chun, P. B.Organista, \& G.Marin (Eds.), Acculturation: Advances in theory, measurement, and applied research (pp. 39-60). Washington, DC: American Psychological Association.

Zea, M. C., Asner-Self, K. K., Birman, D., \& Buki, L. P. (2003). The Abbreviated Multidimensional Acculturation Scale: Empirical validation with two Latino/Latina samples. Cultural Diversity \& Ethnic Minority Psychology, 9, 107-126.

This publication is protected by US and international copyright laws and its content may not be copied without the copyright holders express written permission except for the print or download capabilities of the retrieval software used for access. This content is intended solely for the use of the individual user.

Source: Cultural Diversity and Ethnic Minority Psychology. Vol. 13. (1), Jan, 2007 pp. 10-17)

Accession Number: 2007-00002-002

Digital Object Identifier: 10.1037/1099-9809.13.1.10 